\title{
Esquema de interpretación de la Iglesia en Centroamérica*
}

\section{Ignacio Ellacuría}

I. La Iglesia se encuentra en diversa situación en cada uno de lo palses centroamericanos (incluido Panamá) debido tanto a las condiciones socio-políticas diferentes en cada uno de los países - sobre lodo, en relación con los procesos revolucionarios- como a las diversas configuraciones de las fuerzas eclesiales:

1.1. El elemento determinante para la diferenciación parece ser, desde el punto de vista socio-político, la revolución o los procesos revolucionarios no sólo respecto del proceso histórico mismo, sino respecto también del proceso especificamente eclesial:

a) Nicaragua es la que, desde el punto de vista de la revolución, representa el estadio más avanzado, pues en ella el proceso revolucionario es claramente hegemónico y triun fante, a pesar de las dificultades presentes en su desarrollo.

b) El Salvador y Guatemala presentan unos movimientos revolucionarios y unos procesos revolucionarios, que, sobre todo en El Salvador, han adquirido una fuerza capaz de imponerse en un espacio de tiempo no utópico, si no de una manera total, al menos de manera significativa, que cambiarla el signa socio-político actual.

c) Honduras está más rezagada de modo que su proceso no se ha enderezade ni por el camino de la revolución ni por un camino pseudodemocrático, lo sufi. cientemente consolidado como para imposibilitar a corto plazo el desarrollo de condiciones objetivas y subjelivas revolucionarias.

d) Costa Rica y Panamá, a pesar de sus grandes diferencias, tienen en cor

\footnotetext{
- Texto inédito de 1981.
} 
mún, el haber consolidado relativamente un proceso político, lo suficientemente aceptable como para no facilitar a corto plazo poderosos movimientos revolucionarios, aunque las graves dificultades económicas, sobre todo de Costa Rica, podrían cambiar la correlación de las fuerzas sociales.

1.2. El elemento determinante de la configuración religiosa y, sobre todo, eclesial es la posición y actitud de los distintos estamentos eclesiales respecto del proceso revolucionario: su adhesión o su rechazo, el tipo de adhesión o rechazo, etc. Tal vez esta afirmación es más correcta -en el sentido de más simple y abarcadora - que la de plantear en términos de lucha de clases las posiciones y actitudes eclesiales, aunque de un modo o de otro esto último es lo que podría andar objetivamente en juego, aunque no siempre subjetivamente. En la revolución está en juego una lucha de clases y la supremacía de una sobre otra. Pero la cuestión aparece más como "mayorías populares", "opción preferencial por los pobres" y no implica que el objetivo de la revolución sea la implantación de un sistema marxista-leninista, al menos unívoca y mecánicamente entendido:

a) Nicaragua presentaría una Iglesia profundamente convulsionada como no lo estuvo ni en tiempo de Somoza - bastante somocista-, ni en tiempo de la insurrección -bastante insurreccional, aunque menos sandinista. Todos los obispos menos uno son anti-revolucionarios respecto de la revolución que se da hoy en Nicaragua y como se da hoy; sin embargo, una parte fuerte de Iglesia (un obispo, sacerdotes, fuertes grupos de religiosos, comunidades de base, instituciones) está en favor del proceso revolucionario y colaborando estrechamente con él.

b) El Salvador ha pasado de ser una Iglesia extraordinariamente comprometida con el movimiento popular de liberación a ser una Iglesia en la que aparecen más las fuerzas mediatizadoras cuando no las fuerzas reaccionarias. Una Iglesia que era un paradigma mundial de avanzada y de compromiso se ha convertido, tras el martirio de Monseñor Romero, en una Iglesia contraria a la revolución y condescendiente con la injusticia. El punto determinante en este cambio se debe a la sustitución de Mons. Romero por Mons. Rivera o, quizá más exactamente, a que Mons. Romero no ha podido ser sustituido y las instancias eclesiales se han empeñado en que no sea sustituido y en que su línea sea cambiada. Quedan en El Salvador fuertes grupos de Iglesia (algunos pocos sacerdotes, bastantes religiosos y religiosas, comunidades de base, inmensas siembras a punto de secarse, mecanismos e instituciones) que siguen fieles a la línea de Monseñor Romero. Pero ya el todo y su apariencia son distintos, fuera de la ausencia, antes tan omnipresente, de Mons. Romero. Se han robustecido los mediatizadores, que antes formaban parte de los favorecedores de la liberación popular y siguen firmes los que eran enemigos de Mons. Romero (toda la conferencia episcopal, excepto Mons. Rivera y un buen número de curas y religiosos). 
c) En Guatemala parecería que pocos están contentos con la actual situación política de violencia y represión. Pero todavía son menos los que quieran hacer algo efectivo para detenerla y no digamos para promover la revolución y animar a las organizaciones revolucionarias. No es que no haya algo de esto en las antiguas comunidades de base y en algunos grupos de religiosos, que se ven forzados a salir del país. También está fuera del país el presidente de la conferencia episcopal. Pero, aunque pudiera estimarse bastante coincidencia en la necesidad de que cese la represión -no puede olvidarse la novedad de los dos últimos años en que ha comenzado a un ritmo rápido el asesinato de sacerdotes y la represión de cualquier manifestación de una Iglesia opèrativamente en favor de los pobres-, la coincidencia sería muy reducida a la hora de proponer el camino de la revolución y de la lucha armada para el presente y el futuro de Guatemala. Es probable, como en el caso de Nicaragua, que ante el triunfo de la revolución se lograran hacer presentes poderosas fuerzas eclesiales en favor de ella y es probable también que, si la revolución lo permite como en el caso de Nicaragua, quedarían también fuerzas eclesiales contrarrevolucionarias. Pocos obispos darían un paso decidido de colaboración con revolucionarios de corte marxista, por lo que podría preverse una situación semejante a la actual de Nicaragua. Mientras tanto, no se puede esperar nada abierto en favor de la causa de los pobres, que tenga un cierto matiz revolucionario o simplemente crítico. Hay que conșiderar que los riesgos en la no clandestinidad son muy altos y quizá no muy fructíferos.

d) En Honduras parece que se puede esperar muy poco de la jerarquía. Se llevan 'años trabajando con campesinos y comunidades de base. Aunque este trabajo haya sido capitalizado en alguna forma por la democracia cristiana - contraria en la actualidad a la política de ese partido en El Salvador-, puede estimarse que ahí queda un rescoldo de Iglesia popular $y$, hasta cierto punto, un fondo aprovechable en favor de los procesos revolucionarios. El trabajo está impulsado, aunque generalmente con moderación, especialmente por algunos grupos de religiosos. No deja de ser significativa la prohibición gubernamental de aceptar jesuitas y Maryknolls. Las denuncias por las masacres salvadoreñas en El Sumpul y en los casos de los refugiados son indicios alentadores.

e) Panamá y Costa Rica no pueden enfocarse significativamente por él momento desde el criterio del hecho revolucionario. Esto no quiere decir que no tengan el problema de la opción preferencial por los pobres, pero de momento, esa opción no parece tomar la forma de una lucha revolucionaria. Respecto de la opción preferencial por los pobres, la jerarquía costarricense propende a la interpretación lopeztrujillista de que pobres pueden ser hasta los ricos y de que hay que huir de toda equiparación de los pobres con una clase social constituida como tal por la existencia de una clase burguesa. La jerarquía panameña sería más independiente y lúcida, pero tendría problemas de comprensión y aceptación con lo que podría ser una Iglesia de los pobres. 
I) En todos los casos - con la excepción significaliva de Nicaragua donde la mayor parte de la jerarqura se ha puesto en lucha más o menos abierta contra el gobierno sandinista-, las autoridades eclesiásticas buscan llevarse bien con los gobiemos por muy represivos que sean, lo cual les impide estar en relaciones mínimamente aceptables con la oposición revolucionaria.

1.3. Podría parecer que medir la posición de la Iglesia desde sus relaciones con el movimiento revolucionario es una manera parcial de enfocar el problema eclesial y es, además, una forma de politizar excesivamente a la Iglesia. A esto puede responderse, primero, que estamos tratando de describir una coyuntura, aunque sea una coyuntura profundamente configuradora de los problemas eclesiales; $y$, en segundo lugar, que se da por supuesto que hay mucha actividad de la Iglesia que no es pública ni polftica y que, por tanto, sigue dándose y debe seguirse dando, sea una u otra la posición de la Iglesia ante el fenómeno revolucionario. Lo que sostenemos aqui es que la posición y actitud de la Iglesia ante el fenómeno revolucionario es de gran imponancia, cuando el fenómeno revolucionario es la nota política determinante de una situación. Y esto no sólo o principalmente por lo importancia puramente política del fenómeno, sino por su importancia seológica, ya que la revolución supone la ruptura con una situación de opresión y represión de las mayorías populares y, consiguientemente, pasa muy cerca del problema central del reino puesto en términos de justicia y de mayorias pobres populares. No se trata, por tanto, de un reduccionismo ni tampoco de un planteamiento gratuilo y sin razón. Lo único que hay que hacer es no tratar el problema reductivamente o con falta de crílica, como si el criterio de comportamiento de la Iglesia hubiera de ser el de fidelidad no disculida a un determinado proceso tevolucioriario. Esto puede constituir un peligro real, que exige cautelas, pero no por ello deja de ser un punto de vista importante y necesario, aunque no suficiente.

2. El desafio de los procesus revalucionarios coloca a la Iglesia en una situación de "crisis", pues la obliga a una decisión y a un compromiso que hasta ahora no ha adoptado y para el que se encuentra con graves dificultades:

2.1. Es claro que la revolución, por su propia naturaleza, implica cambios radicales, que pueden exigir la ruptura de actitudes, comportamientos, ventajas $y$ privilegios. No puede pensarse que puede darse un cambio sustancial y radical, en el que el polo hegemónico son las mayorlas populares vanguardizadas por frentes o partidos polfticos con el desplazamiento del polo hegemónico de las clases burguesas y su representación militar y polf́tica, sin que esto ponga en conmoción a lodas las instiluciones, entre ellas a la Iglesia que, como poder social en su conjunto y que como conjunto de obras, muchas de ellas no estrictamente religiosas, está imbricada con toda la estructura social. Se va, si se quiere, de una estructuración social a otra distinta y aun opuesta a la anterior, con la cual la Iglesia se ha habituado a convivir y conforme a la cual ha configurado 
mucha de su aclividad. A veces la dificultad se acrecienta por la connivencia de la Iglesia con los responsables de la situación pasada, lo cual la pone en contra de los movimientos revolucionarios en la hora de la lucha y también en la hora del triunfo, al menos mientras esc ponerse en contra no le cueste mayores desventajas que ventajas.

2.2. Los cambios revolucionarios, en los que se despliega la revolución como cambio radical, facilitan a la Iglesia una conversión fundamental, si es que responde a la llamada de una lucha a fondo contra la injusticia y de una lucha a fondo en favor de los derechos y de las necesidades fundamentales de las mayorías populares:

a) En el proceso anterior al triunfo revolucionario es claro que en países como El Salvador y Guatemala se dan, sobre el fondo de una secular explotación y de un nivel de vida infrahumano de las mayorías populares, una tal extensión e intensidad de la represión contra el pueblo, que obliga a la Iglesia a una posición prorética que la pone al borde del martirio. Por otro lado, la lucha revolucionaria de un pueblo que pelea por su liberación -si es que electivamente se da y en la medida en que se dé- obliga a la Iglesia a comprometerse en esa lucha, lo cual la situa en posición antagónica con los poderes dominantes, entre los que convive. Es posible que la Iglesia quiera resolver este problema "políticamente" y no "proféticamente" o que no admita que los movimientos revolucionarios sean el pueblo en armas, que lucha justamente por su liberación; pero esta misma posibilidad debe ser discernida, de modo que el discernimiento ponga en crisis la actitud que guarda con los evidentes responsables de la opresión y de la represión del pueblo. La evasión por una consideración abstracta del bien común o por llamadas a la prudencia institucional dejan de lado valores cristianos fundamentales, que la Iglesia no podría descuidar. La lglesia no es en principio una instancia que ha de ejercer su misión política principalmente por la vía diplomálica, sino que ha de ejercerla más bien por la vía profética y por la pastoral de acompañamiento. $Y$ esto supone una conversión y un riesgo de hacerla pobre y aun de martirizarla, esto es, de hacerla mórtir.

b) El caso de Honduras presenta otros problernas, no sólo porque el proceso revolucionario es ahí más incipiente y el desartollo de las contradicciones menos agudo, sino porque la propia Iglesia es más "popular" y más "pobre" que la Iglesia en El Salvador y en Guatemala. Cualesquiera sean las excepciones, podrá decirse que la Iglesia ha pecado por omisión o deficiencia -en general poco culpables-, pero no por comisión. Esto plantea la cuestión de si el compromiso eclesial con los pobres exige el compromiso revolucionario con ellos, constituidos o por constituir en clase social. El problema se da también en otros paises, pero es quizá en Honduras donde puede verse con mayor claridad. Muchos sacerdotes, catequistas. delegados de la palabra, religiosas, a quienes no se les puede achacar falta de espiritu y de sacrificio en favor de los pobres, pero que 
no ven la conveniencia y menos aún la necesidad de dar un carácter más político a su misión. Sin embargo, es un hecho indiscutible que Honduras vive una situación no sólo de subdesarrollo sino de explotación, que exige cambios estructurales en los que las mayorias populares debieran participar organizadamente, pues no puede decirse que estén bien representadas por los partidos tradicionales. No parece, entonces, que pueda negarse la necesidad de que la Iglesia adople un compromiso más claro en la denuncia de la injuscicia y de la violencia estruclural y en la cortespondiente animación de grupos populares, que vayen luchando por su liberación, sin que le loque a ella definir cómo van a ser las formas de ese lucha. De todos modos, el caso de Honduras plantea, más que un problema moral, un problema de mayor formación, que tenga más en cuenta la necesidad de mediaciones sociales y, en general, de planteamientos.

c) En Nicaragua, la Iglesia lo deberfa tener mucho más fácil y, sin embargo, no lo está teniendo por falta de visión de varios obispos y por la presión de lo que pudiéramos llamar la Iglesia burguesa. El problema es sin duda complejo y tiene mucho que ver con el presunto carácter marxista-leninista de la revolución sandinista. El marxismo-leninismo presenta dificultades intolerables tanto al imperialismo norteamericano que no puede tolerar en su cercanía ni la sombra del marxismo, sobre todo si tiene presencia cubana y soviética, como a la burguesla que ve en él la negación de su poder hegemónico. Y presenta también dificultades ideológicas a la Iglesia, que van desde el ateismo, la lucha de clases, la dictadura totalitaria del proletariado asumida por una vanguardia partidista hasta la critica de toda religión. No se distingue adecuadamente - a veces no sin responsabilidad por parte de los nuevos hombres en el poder- entre la dirección fundamental que pretende logros fundamentalmente más valiosos, como son el mayor bien de los más pobres y la soberanfá e independencia de la nación frente al anterior imperialismo dominante y el modo como todo esto se lleva a cabo con grandes dificultades reales y con unos mecanismos que admiten discusión y crítica. Por esa falta de comprensión, la Iglesia, la parte de ella que se opone a la revolución tal como se está dando, se estŕ aliando con los enemigos burgueses de la revolución y con los intereses norteamericanos y está siendo apoyada por la burguesía en todo aquello que vaya a debilitar el carácter revolucionario del proceso. Contrarresta esta posición dedicándose también al cultivo y exacerbación de una religiosidad popular así como al apoyo populista a los obispos. Tendriamos asl un cultivo conjunto de los intereses de la clase burguesa y de todos los antirrevolucionarios junto con la atención a sectores muy sencillos, a los que se les hace sentir sutilmente la oposición de la revolución sandinista-comunista con lo que es su religión y sus devociones. Pero hay otra parte fuerte de la Iglesia, que no tiene miedo a la revolución, sino que la apoya tanto en el plano de lo intelectual, en el plano de la colaboración pública - curas y religiosos insertos en tareas del Estado- y en el plano de las comunidades de base, a las que se explica $y$ en las que se fomenta su vocación polltica y su 
compromiso revolucionario. Ninguna de las dos posiciones corre peligro de persecución propiamente dicha, aunque la parte favorecedora de la revolución siente fuertes presiones eclesiásticas para hacerlo, mientras que la parte contraria empieza a sentir no dificultades, pero s'́ restricciones.

d) Costa Rica y Panarná, como ya hemos dicho, no se encuentran todavia con el desafío revolucionario, aunque sí con el desafío de constituirse como Iglesia en opción preferéncial por los pobres, que desde luego tienen, aunque en forma distinta a los demás palses, un volumen notable. Costa Rica evade este problema a través de unos obișpos y de un clero sumamente instalado y bastante aburguesado y mediante una religiosidad cultual muy extendida. Panamá se ve absorbida por su falta de clero y por el carácter centralista y urbano que da al conjunto de la nación su capital y su naturaleza de nación de servicios con sus problemas de consumismo y dc secularización. Ambos países y sus jerarquías más representalivas están preocupadas porque no se les importen ni los problemas eclesiales, ni la teología y pastoral de los demás países centroamericanos; cn lo cual parecen coincidir con sus correspondientes autoridades civiles, que temen verse introducidas en el torbellino revolucionario centroamericano. Dicho de otra forma, tanto Costa Rica como Panamá se consideran, en la práctica, muy poco centroamericanas, amparadas en que su estructura social y su trayectoria histórica son muy diferentes.

2.3. A pesar de la diversidad de situaciones se pueden plantear una serie de rareas, a través de las cuales la Iglesia debería responder al desafío revolucionario, consciente de que tras el desaflo revolucionario está el desaffo de unas mayorias populares, que interpelan a la Iglesia asl como también interpela al Estado:

a) La Iglesia debe vivir eficazmente, debe anunciar y realizar, que Dios no es sólo Señor de los individuos y de las conciencias, sino rambién de la sociedad y de la historia Esto no debe llevar a la antigua sacralización del Estado ni a relaciones oficiales de la Iglesia con el Estado, sino a la preocupación porque las estructuras sociales -especialmente las económicas- y aun las estructuras estatales se constituyan en beneficio de la totalidad, pero no de una totalidad abstracta e indiferenciada y menos de una totalidad configurada sobre las pretensiones de una clase burguesa dominante o del capitalismo, sino de una totalidad configurada desde las necesidades de las mayorias populares. Esta es una exigencia del reino de Dios y no una exigencia surgida de razonamienlos jurfdi$\cos$ y morales; quiere decirse con esto que es una exigencia estrictamente teológica y religiosa y no meramente una extensión politizada de la doctrina social de la Iglesia o algo periférico a su misión central. No se trata con ello de politizar a la Iglesia, sino de encamarla e historizarla.

b) Desde esta confesión de Dios como Señor de la historia y, más precisamente, de Jesús como Señor de la historia (la distinción no excluyente es impor- 
tante, porque con ella se especifica de qué Dios se trata y de que teo-logfa se ha de imponer), es evidente la necesidad de una opción preferencial por los pobres. Esta opción preferencial por los pobres no se confunde formalmente con una opción de clase, aunque puede coincidir materialmenle, porque la opción preferencial por los pobres es "mayor" que la opción de clase, "siempre mayor". pero la opción de clase puede ser la forma políica y social que más se acerca y que más conduce a lo exigido histónicamente por la opción prefrencial por los pobres. Lo que si es claro es que, en situaciones como la de Centroamérica, caracterizadas desde la realidad de la revolución, la opción de clase burguesa está mucho más alejada de la opción preferencial por los pobres que la opción de clase explotada. Con menor evidencia pero no con escasa razonabilidad puede estimarse que son más conformes con la debida opción eclesial aquellos regímenes políticos configurados desde la opción de clase explotada que los configurados desde la opción de clase burguesa. Y en esto no conviene engañarse porque los presuntos valores occidentales y cristianos de los reglmenes politicos que en nuestros paises responden a los intereses del capitalismo y de la clase burguesa podrán ser occidentales, pero no son cristianos porque sólo los más favorecidos pueden vivirlos y disfrutarlos. Esto no obsta a que quepa una dura discusión y una no menos dura crítica de cómo debe configurarse un régimen político que quiera defender los derechos y las necesidades de la clase explotada. Y lambién la Iglesia debería aquí - aunque de una forma derivada, porque su centro no estarfa en la configuración técnica del régimen en cuestión, sino en la promoción de una opción preferencial por los pobres- alentar una originaljdad creativa. La Iglesia no debería tener grandes miedos si es que un régimen busca de verdad satisfacer las necesidades reales, los intereses verdaderos y la profunda dignidad de las mayorías populares; debería ponerse en esa misma línea y ser alentadora crítica de él e ir incluso delante de él en las exigencias utópicas de un sano profetismo, dejando los papeles de "moderación" a otras instancias, si las hay.

c) Los dos puntos anteriores justifican una determinada configuración de la Iglesia como institución de modo que se configurara como verdadero pueblo y como verdadero pueblo de Dios. En una situación como la que predomina en el área centroamericana, esta configuración debería tener, por lo menos, estas características: a) opción preferencial por los pobres efectiva; b) encarnación histórica en las luchas del pueblo por la justicia y la liberación; c) introducción de la levadura cristiana en las luchas por la justicia; d) la persecución por la causa del reino de Dios en la lucha por la justicia.

d) La distinta siluación de los paises centroamericanos respecto de la revolución exige una priorización de fareas y una aplicación llena de discernimiento a las coyunturas. Aquí sólo pueden proponerse unos apuntes tentativos más como puntos de reflexión y de orientación que como puntos de decisión: 
+ La situación de Nicaragua se caracteriza en principio porque el FSLN y el gobierno de reconstrucción se han constituido como un régimen de clase, en el que la opción es en favor de las mayorías populares. Caben discusiones sobre si la estructuración política y técnica de esa opción es la debida y si se ha ido en ella demasiado lejos 0 , al contrario, se ha quedado corta. Por otro lado, es menester reconocer que la tarea propuesta en favor de las mayorias ha encontrado gravisimas dificultades: una economía ya de por sí débil, destruida y esquilmada; un aparato estatal en cero; un fuerte peligro contrarrevolucionario; un cerco del capitalismo norteamericano dispuesto a ponerle en dificultades máximas al régimen sandinista; unas masas poco preparadas para la reconstrucción... Esta situación, como ya hemos insinuado antes, ha llevado a ensañarse con las dificultades, sin reconocer ni la corrección cristiana del propósito fundamental ni la prudencia y generosidad con que generalmente se ha portado la revolución -incluso con sus enemigos, no ya digamos con sus adversarios. Parecería, entonces, que la Iglesja no está actuando correctamente en su conjunto, obligando entonces a una parte de ella a politizarse aparentemente demasiado para contrartestar el des-apoyo positivo de la otra parte. La Iglesia en su conjunto debería volver al espiritu de la pastoral conjunta de noviembre de 1979; debería apoyar la dirección fundamental de la revolución en sus propósitos principales, debería colaborar con ella y ayudarla en lo posible a superar sus deficiencias con espíritu constructivo y no con nimiedades críticas. No debería hacerle el juego ni directa ni indirectamente a los intereses burgueses ni al capitalismo norteamericano. Su ayuda no debería ir tanto a la dirigencia sandinista y estatal, sino a evangelizar al pueblo para que colabore en la reconstrucción y ponga lodo su espíritu y creatividad cristianos en ella. Debería ser contemplativa en la revolución, esto es, debería encontrar a Dios en la revolución, al Dios crucificado en sus pobres, de modo que cuando no se manilieste lo haga aparecer. No debe ponerse a la defensiva y menos al ataque en relación con el poder revolucionario. Sin abandonar la lucidez y la crílica. Debería ser más revolucionaria que la propia revolución en poner al pueblo por encima de cualquier forma de organización, también de la organización eciesiástica; en favorecer, sin embargo, la organización del pueblo, aunque no necesariamente a través de los cauces oficiales, pero tampoco con intenciones antagónicas; en infundir valores cristianos a la estrucluración de la sociedad y en construir el hombre nuevo con una experiencia y unas perspeclivas que no puede tener la revolución sandinsta.

+ En El Salvador. la Iglesia debe eslar preparada para responder revolucionariamente al triunfo de la revolución. A pesar del extraordinario bajón que ha dado en el último año, no puede negarse la extraordinaria contribución de la Iglesia salvadoreña al proceso revolucionario. Ahí están las comunidades de base campesinas; ahí está todo un mensaje liberador en choque 
permanente contra la injusticia y la represión; ahl están sus mártires, Monseñor Romero, once sacerdotes, cientos de catequistas y delegados de la palabra, todos ellos anunciadores y víctimas de una sociedad nueva; ahl está la labor intelectual de instituciones y hombres de inspiración cristiana... Todo esto debe ser una garantía para los revolucionarios y para la revolución, a pesar de que otra parte de la Iglesia ha sido cobarde y reaccionaria. Pero la Iglesia no puede dormirse en lo que ha sido, porque entonces quedara cada vez más lejos del futuro revolucionario y de su incidencia en él. Por eso debe intentar recuperar su pulso profético y martirial no para tener víctimes, sino para tener eficacia y cumplir con su misión. La Iglesia, en consecuencia, debería poner todo su peso: a) en desenmascarar como falsa e injusla la solución actual representada por la junta militar democrata cristiana y propugnada por el imperialismo norteamericano; b) en buscar una solución negociada que acorte y suavice los dolores de parto de la nueva sociedad; c) en captar, presentar e influir sobre el proyecto histórico popular para hacerlo mejor y para ayudar a que sea asimilado por la conciencia colectiva; d) en estar mucho más cerca de los hombres revolucionarios y del pueblo en lucha teniendo sacerdotes y agentes de pastoral que trabajen evangélicamente en las zonas controladas por el FMLN y teniendo conexiones eficaces con los hombres que dirigen la lucha y que proyectan la solución futura. La Iglesia harfa mal en acomodarse a las exigencias y a las ventajas de lo que son las zonas actualmente dominadas por el gobierno, como si eso fuera actualmente la realidad del pars $y$, menos aún, la legalidad y, mucho menos aún, el camino para el futuro deseable. Es mejor que se equivoque políticamente apostando por las mayorías populares en lucha a que se equivoque cristianamente defendiendo un centrismo 0 un posibilismo que alarga, sin protesta cristiana, el dolor y la desesperanza del pueblo. Esto no significa que se entregue con los ojos cerrados al proyecto popular $y$, menos aún, a las maniobras politicas para ponerlo en marcha, pero sf exige que historice lo que es hoy en El Salvador la opción preferencial por los pobres, punto sumamente dificil dada la jerarquía existente y el reblandecimiento demócrata cristiano de sacerdotes y agentes de pastoral. En una palabra, hay que resucilar a Monseñor Romero.

+ En Guatemala, la Iglesia verdadera tiene que adoptar características de clandestinidad y de calacumba. El espacio político y social que se le ofrece por parte de las fuerzas represoras es estrechísimo, mucho más estrecho que el de El Salvador. Los que se quejan injustamente del poco espacio de la Iglesia en Nicaragua deberian reflexionar comparativamente sobre el espacio que la Iglesia verdadera tiene en Nicaragua para anunciar una fe comprometida y para promover la justicia cristiana; esto mostrarfa más que otra cosa la verdad de ambas situaciones y la autenticidad de la Iglesia. La expulsión del presidente de la conferencia episcopal y el asesinato en pocos meses de diez 
sacerdotes, a los que en su mayor parte sólo se les pueden atribuir tareas de acompañamiento a las mayorfas populares, es demostración palmaria de lo que es la situación política de Guatemala y de lo que es el espacio vital que le es permitido. En estas condiciones parece necesaria una reunión eclesial en que se discuta a fondo la misión de la Iglesia en la coyuntura actual, una misión que responda a las exigencias de negación activa de la actual situación dominante y a las exigencias de animación de un proyecto que responda a las necesidades y a los derechos de las mayorias marginadas y explotadas. Esto puede exigir un desdoblamiento de la actividad pastoral: por una parte. la actividad realmente posible y exigible en el campo abierto de la actividad pública; por otra, una pastoral de acompañamiento en el sector clandestino tanto de las fuerzas revolucionarias como, sobre todo, de tanta población abandonada por la sistemática persecución a la Iglesia, que trabaja abiertamente. La Iglesia, en consecuencia, debe preguntarse seriamente: a) cuál puede ser su contribución a que se termine pronto con el actual régimen de explotación y de exterminio; b) cuál puede ser su contribución a enconurar, fomentar y publicitar la solución posible en Guatemala; c) cuál debe ser la forma de asistencia pastoral en las zonas donde el gobiemo no tolera la presencia pública de la Iglesia; d) qué forma debe tomar la pastoral de acompañamiento en torno al pueblo que se mueve en favor de los movimientos revolucionarios. Aquí hay más preguntas que respuestas indicalivas, pero hay vinculaciones y personas que pueden ir avanzando políticas de pastoral para el momento presente y para el futuro. Una Iglesia puesta mayoritaria y visiblemente al servicio del status quo deberla iniciar una larga, penosa y difícil conversión.

+ En Honduras, la Iglesia debe profundizar su compromiso con el pueblo, especialmente con los campesinos. Profundizar y purificar. La Iglesia hondureña, pionera en algún sentido de las comunidades de base campesinas y de los delegados de la palabra, tal vez se ha quedado un poco rezagada, quizá porque nació demasiado pronto y en otras circunstancias eclesiales y políticas. No le toca a la Iglesia propiciar movimientos ni mecanismos de revolución, pero sí encarnar históricamente el anuncio de la palabra liberadora. Un robustecimiento de una auténtica Iglesia popular que aguijonee y vigorice a la Iglesia establecida, un esclarecimiento de lo que los cristianos deben hacer hoy en la coyuntura hondureña y una participación más lúcida de las instancias más visibles de la Iglesia en el enjuiciamiento de la coyuntura nacional, económica, social y polf́tica, serlan tareas necesarias y posibles. Exigirlan esfuerzo, pero de momento no grandes riesgos de persecución. Pero la palabra resumen serfa profundizar. Profundizar teológicamente lo que es la opción preferencial por los pobres y profundizar sociológicamente en las mediaciones requeridas para poner en marcha un proyecto popular que se acomode a las necesidades y exigencias del pais. El experimento de las próxi- 
mas elecciones podría ser un buen arranque del análisis.

+ La Iglesia de Cosia Rica vive del pasado y en el pasado; para ella no significa nada la experiencia del resto de Centroamérica. Pionera en los tiempos de Mons. Sanabria y en las reformas sociales se ha estancado en un ritualismo y en un sacramentalismo poco eficaces no sólo para la tranformación de las estructuras, sino incluso para la conversión personal. La última pastoral de los obispos en un año de grave crisis económica y de incipientes tensiones sociales graves ha sido sobre los problemas ecológicos, aunque anteriormente tuvieron otra sobre la realidad nacional. La Universidad de Costa Rica en vez. de ser un centro de incitación a la critica y al cambio social es, para pasmo del área, un centro de conservadurismo social. En estas condiciones, lo que sería exigible a la Iglesia de Costa Rica es que viva en el presente y se enfrente lúcidamente con el futuro de un país acostumbrado a vivir sobre sus posibilidades, en franca crisis ecónomica y con miedo a buscar las soluciones radicales que exige su situación. La Iglesia debe abandonar su configuración burguesa y su exhibicionismo trasnochados y debe enfrentarse con la realidad y con las exigencias de lo que significa la opción preferencial por los pobres. Es posible que haya un modo costarricense de hacer las cosas y que en ese modo haya cosas que deban conservarse -eso que indiferenciadamente se llama el talante democrático y acogedor de los costarricenses - en la transformación; tampoco hay por qué echar por la borda la asistencia masiva de los fieles a los oficios religiosos. Pero nada de esto impide que se llegue a ver la imperiosa necesidad de un profundo y colectivo examen de conciencia y un plan de Iransformación siempre difícil, dada la jerarquía, el tipo de clero y el tipo de formación en el seminario. Una cierta fuerza de los religiosos y de su confederación, la acción del ITAC y de otras instituciones, mal vistas hoy por la jerarquia, podrían ser el fermento del cambio.

+ Las tareas de la Iglesia pananteña son más difíciles de precisar, aunque el tema central sería el de alinearla con Medellín y Puebla y no meramente con un Valicano II deshistorizado. La Iglesia panameña debiera escuchar mejor los clamores y las exigencias de la Iglesia popular. Por otro lado, se encuentra con el desafío de dos sectores muy distintos: el de la capilal y la zona del canal y el del campo y de los indígenas. También es importante lo que puede y debe hacerse ante el singular régimen político y económico que desde hace años tiene Panamá. Todo ello hace que en Panamá lo que es el pobre y la pobreza y, consiguientemenie, lo que es lucha por la justicia y la liberación tomen características propias. Lo cual, si impide la imitación mecánica de lo que ocurre en otros lugares del istmo, no permite evasionismos culturizantes o puramente administrativos. Está, asi mismo, el gravisimo problema de la escasez de recursos pastorales autóctonos, por lo que en sí mismo significa de acusación a la pastoral vigente y por lo que dificulta una acción pastoral 
integral que tenga en cuenta al hombre $y$ a la estruclura social.

3. Hay una serie de constantes que se hacen presentes en la realidad eclesial centroamericana y que son necesarias para su interpretación y transformación. Sin estar claros sobre ellas es imposible que tanto la una como la otra sean las correctas:

3.1. Está la acusación más o menos oficial de que los sectores de la Iglesia que propugnan la necesidad de cambios radicales y urgentes son sectores que politizan, horizontalizan y reducen la misión evangelizadora de la Iglesio. Los sustentadores de esta acusación querrian que la Iglesia se mantuviese prácticamente en terrenos espirituales e interiores, propiciando mucho más —cuando no exclusivamente- la conversión personal que la transformación de las estrucluras. No es que no hablen de esto último, pero lo consideran como cosa de los otros, a lo más de los políticos cristianos. Es una acusación que tiene algún fundamento en las posiciones de algunos sacerdotes, religiosos, comunidades de base, elc., que han abandonado su misión especifica para dedicarse exclusivamente a tareas polfticas. Es, por tanto, una advertencia que ho de tenerse en cuenta, pero que no puede servir de pretexto y escapatoria para no cumplir con las exigencias intrínsecas de la fe misma. Como hay un peligro de horizontalización y de reduccionismo en un lado hay el peligro de verricalización y de reduccionisno ent el otro; con el agravante de que si aquél lleva a una politización que favorece a las clases populares, éste lleva a una politización que favorece a las clases dominantes. Puede haber tensiones beneficiosas entre quienes pugnan más por la encarnación histórica y por quienes pugnan más por la transcendencia histórica, pero siempre que esas tensiones respeten unas exigencias esenciales dentro de la perspectiva cristiana del reino de Dios. Los partidarios de la encarnación histórica lo que quieren encarnar es el reino de Dios, el mensaje de Jesús y de los profetas, la palabra de los apóstoles, la mejor tradición de la Iglesia. Puede ser manipulado su esfuerzo, pero no puede ser negado que hasta ahora ha sido mucho más manipulado el esfuerzo de quienes se profesan verticalistas, pero cuyo verticalismo ha sido utilizado para pasar por alto y a la carrera sobre el pecado de la historia. Es hora de que no se recurra al peligro del reduccionismo horizontalista y politizante para evitar compromisos y riesgos, exigidos por la santidad de la Iglesia y por la vocación apostólica. En el fondo, la burguesía y la democracia liberal son mucho más horizontalistas y materialistas que las revoluciones, al menos en el momento en que éstas sacrificadamente, heroicamente luchan contra estados de opresión y de represión entregando vidas y porvenires en favor de la causa de la liberación y, en último término, de los más pobres y necesitados.

3.2. Esla piedra de escándalo que es la revolución se convierte en piedra de tropiezo que divide la Iglesia. Este tema de la división de la Iglesia ya ha sido tratado con profundidad (cfr. Jon Sobrino, "La unidad y el conflicto dentro de la 
Iglesia", en Resurrección de la verdadera Iglesia, Santander, 1981, pp. 210-242). En este esquema vamos a recoger algunos aspectos teórico-prácticos más útiles para la interpretación y transformación de la lglesia en Centroamérica:

a) Está la división entre lo lglesia popular y la lglesia institucional. Aquélla estaría más cerca de los procesos revolucionarios y ésta más del desorden establecido: la Iglesia configurada por las exigencias revolucionarias de los pobres y la Iglesia configurada por las exigencias conservadoras de los ricos. De esia división hay que decir: a) que no es técnicamente una división entre dos iglesias en el sentido de dos instituciones eclesiásticas separadas, pues por lo general no hay intención alguna de crear olra institución, sino de santificar la existente; b) que no es una división entre Iglesia jerárquica e Iglesia no jerárquica, que dejara fuera a los obispos, a los sacerdotes, a cuantos tienen jurisdicción, pues no pretende desconocer la estructura jerárquica de la lglesia, aunque cuestione el modo de actuar de la jerarquía y mantenga ante ella no relaciones servilistas y aduladoras sino libres y maduras según el espíritu de Cristo; c) la Iglesia popuLar, configurada generalmente en comunidades de base se alimenta - en los casos que el proceso revolucionario sea un elemento delerminante de la coyuntura histórica- con miembros que se comprometen con las luchas populares, con gentes concientizadas del pueblo, y por eso entra en conflicto con otros grupos o personas eclesiásticos constituidos por enemigos de la revolución; d) la Iglesia popular se compromete además políticamente a impulsar los procesos revolucionarios, a hacerlos más cristianos y a alimentar cristianamente a quienes se dedican a ellos; e) la Iglesia popular llama a la conversión a la Iglesia entera y se convierte en grupo proférico que interpela tanto a la sociedad como a la Iglesia y a la revolución, dejando toda pasividad y minoría de edad; f) por eso, no se trata de una diferencia política, sino de una diferencia teológica, pues en el fondo la discusión está en donde se oye más y mejor el reclamo del espiritu de Jesús, que dio a los pobres un lugar preferencial; g) esto no obsta a que haya en ocasiones aspeclos y opciones políticas distintas, que no tienen alcance estrictamente teológico y que, por tanto, no deberían tomar un peso decisjvo y menos excluyente.

b) Esía la contraposición entre los religiosos con su propia autonomía y fuerza y los obispos con sus canales jurisdiccionales. Es claro en América Latina y, desde luego, en Centroamérica, que los religiosos suponen en la pastoral quizá la fuerza más grande y que, en casos importantes, representan posiciones más avanzadas y comprometides que los no religiosos. Hay sin duda congregaciones casi enteras más retrasadas y mundanizadas que muchos sacerdotes seculares y otros agentes de pastoral; hay muchos obispos salidos de congregaciones y ordenes religiosas que en nada se distinguen de otros obispos. Pero no puede desconocerse que en conjunto, los religiosos representan una fuerza profética mayor con sus carismas propios y con su peculiar organización. Este carácter es 
reconocido por el Vaticano U., por Medellín y Puebla y no es de extrañar si se estudia el origen siempre reformista de los institutos religiosos. Estos grupos enfrentados con frecuencia a obispos, cuya condición humana, cristiana y ministerial deja mucho que desear y aun a conferencias episcopales de poca calidad, que entienden la autoridad y la obediencia en la Iglesia con criterios poco evangélicos, son vistos como un peligro para la unidad y la ortodoxia de la Iglesia, cuando son muchas veces uno de los locos principales de renovación y de compromiso.

c)Está también el hecho del llamado magisterio paralelo sea de los religiosos sea, mós propiamente, de los teólogos. El problema no es exclusivo de América Latina, aunque en este continente tome características especiales. Los teólogos de la teología de la liberación, fuertemente conectados con las comunidades de base y con los movimientos más comprometidos de las congregaciones religiosas se ven acosados por obispos no tanto desde la fe y desde el auténtico magisterio, sino desde unas interpretaciones teológicas simplistas, que responden normalmente a una teología trasnochada y, además, muy poco cultivada. No se trata, entonces, de dos magisterios enfrentados, sino de dos teologias enfrensadas, una más viva, creadora y consonante con la realidad revolucionaria y otra más académica (?), repetitiva y formal, que no ha incorporado el hecho de una praxis histórica como elemento esencial de su reflexión. Como en la Iglesia hay lugar para los profetas, hay lugar también para los doctores. Y si la Iglesia necesita de pastores y de maestros que den lo que podría llamarse autenticidad canónica a la doctrina, necesita no menos de profetas y doctores que respondan a lo que es exigencia de la creatividad cristiana y a lo que es exigencia de la novedad hisı́rica. En la oposición CELAM-CLAR, CELAM-té́logos de la liberación no puede echarse la mayor culpa a la CLAR o a los té́logos de la liberación. Y si el problema se ha agravado con la última administración del CELAM, hay que preguntarse por que.

d) Ver sodos estos problemas como lucha de clases, si se entiende la lucha de clases como algo promovido por el comunismo internacional para destruir a la Iglesia o para manipularla láclicamente, es una simpleza. Otra cosa sería verlos en pare como reflejo en la Iglesia de una lucha de clases que se da objetivamente en la sociedad. Se supone a veces que un planteamiento clasista es siempre un planteamiento proletario y que un planteamiento burgués no es un planteamiento clasista. En general, los partidarios de un planteamiento no clasista to que hacen es siluarse en un todo que no es sino una parte magnificada o una perspectiva parcial totalizada, mientras que los que formulan explfcitamente sus análisis teniendo en cuenta la división y el conflicto de las formaciones sociales se empeñan en entender el lodo desde una parte, pero al hacerlo explícila y sistemáticamente configuran y cualifican el todo, pero no lo reducen, al menos en principio, pues reconocen la existencia de un todo dialéctico, en el que una parte reclama a la otra y constituye con ella una unidad, un todo 
dialéctico, cualificado por esa "relación" opuesta, negativa entre las dos parles. Reconocida la división y la lucha se reconoce el todo real, tal como es; mientras que desconocida esa división y lucha, se acepla sin más la parte o clase dominante como si fuera el todo 0 , al menos, se acepta el todo tal como está configurado por la clase dominante. Sin olvidar que la lucha de clases en nuestros parses es originariamente una lucha explotadora y opresora iniciada por la clase dominante, a la que responde la clase dominada como su lucha revolucionaria, liberadora de la opresión y de la represión.

3.3. La revolución en Centroamérica se presenta con caraclerísticas marxistos, lo cual para algunos, incluida la jerarquia, supone la imposibilidad de toda colaboración de la Iglesia con los procesos revolucionarios. Ahora bien, este planteamiento no es adecuado y lleva a falsas posiciones ante la revolucion:

a) Hay un planseamiento falso al identificar revolución con marxismo o régimen comunista. Es cierto que la revolución cubana, de gran influjo en las revoluciones centroamericanas, es marxista-leninista. Pero ni aun en ese caso ha de identificarse revolución y comunismo, aunque así lo hagan los propios dirigentes revolucionarios. La revolución no consiste ni debe consistir formalmente en la instalación de un régimen maxxista-leninista, sino que la instalación de ese régimen será en el mejor de los casos un medio para la revolución o un esquema abstracto de revolución. La revolución no debe verse como un medio para propagar el comunismo, sino que debe verse a éste como un medio para aquélla. Esta concepción es importante. Y sobre ello debiera insistir la Iglesia. La revolución implica el traslado del poder - no principal ni exclusivamente el poder polfítico- al pueblo, a las mayorias populares explotadas y reprimidas; el marxismo-leninismo es un modo de lograr eso y vale sólo en cuanto lo logre. Lo que hay que añadir es que sólo una historización a fondo del marxismo-leninismo, que tenga en cuenta verdaderamente el conjunto de condiciones reales de una sociedad determinada, sería un marxismo-leninismo válido. Hasla el punto que una determinada revolución puede exigir formas de algún modo marxistas, pero que pueden ser original y creadoramente distintas a las dadas hasta ahora. Especialmente en sus relaciones con el cristianismo y con la Iglesia.

b) Esto lleva a la necesidad de desabsolutizar el marxismo. Tanto las jerarquias comunistas como las jerarquías eclesiasticas caen con facilidad en la absolutización del marxismo. Para las primeras es el bien absoluto, que no necesita correcciones y que debe ser impuesto a como dé lugar; para las segundas es el mal absoluto, que es intrínsecamente malo e incorregible y que debe rechazarse también a como de lugar. Este planteamiento es por parte y parte falso y lleva a consecuencias prácticas inaceptables. El marxismo no es un absoluto y debe ser aceptado o rechazado según haga bien o mal al bien común, visto desde las mayorlas populares y desde las clases oprimidas. Aunque este bien o mal tiene un cierto margen de valoración más o menos subjeliva, tiene 
Lambién un amplio margen de verificación histórica en cada una de las situaciones. Pero el criterio de verificación no debe ser lo que es bueno para la institución del partido u organización o lo que es bueno para la institución eclesiástica, sino lo que es mejor para el pueblo y para el reino de Dios.

c) Por parte de la Iglesia como lal están fuera de lugar las críticas lécnicas a los posibles fallos técnicos en la conducción de la revolución, sea en la hora de la lucha sea en la hora del triunfo. En esa conducción se dan valores morales que son también campo de la Iglesia, pero hay muchos aspectos técnicos que no entran. Lo que se quiere decir con esta advertencia obvia es que no se apoya la Iglesia para rechazar una revolución en sus fallos técnicos, como si éstos fueran fallos morales. El juego crítico, que lo debe haber, tiene que ser extremadamente IImpio y justo.

d) Lo Iglesia debe ser asimismo muy sincera tanto en juzgar lo que es bueno para el pueblo o para los "pobres" y no caer en el juicio burgués de lo que es bueno para los más dotados o para los de mayores recursos. Debe ser muy sincera también en juzgar lo que es bueno para el reino de Dios y lo que es bueno para ella como inscitución. Es muy probable que una sociedad realmente centrada en el mejoramiento de las mayorf́as populares, cuando éstas viven en niveles infrahumanos, exija del resto de la población, acostumbrada a niveles altos, una cuota de sacrificio grande. Exija asimismo a la Iglesia a que cambie no sólo estilos de vida poco conformes con lo que es el nivel de las mayorlas populares, sino también pautas de trabajo, que han sido establecidas para influir desde patrones burgueses.

e) Aun con todas las reservas y precauciones oficiales, la Iglesia no rechaza la colaboración práctica con hombres y regimenes marxistas, en todo lo que es bueno, justo y conduce al bien común. Pero debería trator de corregir y perfeccionar los regímenes marxistas, pero no con críticas externas -desde fuera- conflictivas, sino con superaciones internas -desde dentro del proceso- constructivas. Esto puede hacerse desde dos perspectivas distintas: desde la perspectiva de que el proyecto es en lo fundamental correcto y en eso se lo apoya, aunque se lo critica en sus fallos; o desde la perspectiva de que la Iglesia, como Jesús, no tiene miedo de comer con los que la sociedad religiosa estima como pecadores y publicanos, siempre que éstos no sean opresores de los más pequeños y débiles, en cuyo caso no cabe sino la ruptura y el choque frontal.

f) Ni qué decir tiene que la Iglesia no debe dejarse manipular y que su punto de mira no debe ser favorecer un partido o un régimen, sino un proceso, en lo que tiene de mejoramiento de la suerte de los más desposeídos y en lo que pueda tener de historización más adecuada del reino de Dios. No debe permitir identificaciones que privan de libertad crílica o que no dejan campo para el anuncio específico y explícito de la salvación ofrecida a todos los hombres en Jesús. 
g) Los puntos más graves que podrian ser tema de discordia de un régimen marxista con la fe cristiana serían el de un materialismo ateo que irla a la críica de rada religión y que podría poner If́mites a la justa libertad de la Iglesia y la de una concepción de la sociedad y de la historia que pondria en entredicho teorico y en imposibilidad práclica valores fundamentales, que chocaran con la dignidad de la persona y fomentaran una violencia injustificada. Son puntos en que, para nuestro propósito, no importa tanto una discusión teórica de si esto es o no es esencial al marxismo como un análisis práctico que se hiciera la siguiente pregunta: ¿se da esto en los movimientos revolucionarios y en que medida? ¿se prevé que se dé en una medida mayor, que pudiera llegar a ser peligrosa? La respuesta referida a Nicaragua tiene que ser de momento negativa y, sin embargo, la Iglesia se muestra mucho más permanentemente a la ofensiva de lo que era usual en ella durante el somocismo, que contradecía realmente mucho más a fondo los valores cristianos. La respuesta referida a los movimientos revolucionarios de Guatemala y El Salvador debe ser también negativa y de nuevo mucha parte de la Iglesia pone mayores reticencias a esos movimientos que a los regímenes imperantes en El Salvador y Guatemala, cuyas características fundamentales son una violencia de proporciones espantosas y una puesta al servicio -más en Guatemala que en El Salvador- de las clases dominantes, que deja a la mayoría de la población en condiciones de vida inhumana. Pero lo que aqui queremos dejar subrayado es que lo importante no es si los revolucionarios son como personas marxistas-leninistas o ateos, sino si su conducla política y sus acciones polfucas son justas o no, responden a las exigencias reales o no, respetan los derechos fundamentales o no. La lucha ideológica puede ser importante, pero mientras dejen a la Iglesia responder ideológicamente no tiene por qué preocupar tanto.

h) Por la cuenta que les trae a los regímenes revolucionarios ya se cuidarán, si no quieren caer en un totalitarismo improbable, dado que vienen de luchar contra otro totalitarismo, de no mantener un maxismo onodoxo y mecánico. En nuestros paises es un hecho importante la exigencia de una religiosidad popular que si es contradicha por un régimen puede convertirse en una poderosa fuerza popular de rechazo a ese régimen. Por otro lado, la presencia en las luchas revolucionarias y en la reconstrucción revolucionario de auténticos cristianos y de revolucionarios auténticos pueden ayudar mucho no sólo a la clarificación de este problema, sino a su solución. Por lado y lado, la pregunta no debe ser qué de malo o de contrario tiene la otra parte y cómo se lo puede destruir, sino qué puede aportar el marxismo al cristianismo y qué puede aportar el cristianismo al marxismo. Un planteamiento positivo por ambas partes serfa mucho más superador y mucho más eficaz para ambos. Cerrarse en ese punto es un error teórico y un error histórico que puede traer funestas consecuencias tanto al marxismo como al cristianismo, y, sobre todo, al pueblo y a la sociedad. 
3.4. Hecho importante para las iglesias de Centroamérica es la persecución. Lo persecución es signo de ausenticidad y santidad, siempre que sea por causa del reino. Pero la persecución está también estrechamente relacionada con la revolución. Esta unidad de persecución a la Iglesia y persecución a la revolución plantea problemas importantes:

a) Hay una persecución por causa de la revolución. El significado politico de este hecho es claro: se quiere aniquilar a quienes son amenaza real contra el régimen dominante; a veces se pretende dar un color teológico a esta salvaje lucha de aniquilación tildando a los revolucionarios de comunistas, ateos, etc. Pero en cuanto la revolución representa un esfuerzo sacrificado, que pone en riesgo la propia vida para que los más pobres tengan vida y dignidad, entonces, la persecución por causa de la revolución tiene un profundo sentido teológico y cristiano, no primariamente porque en ella hay a veces una clara inspiración cristiana de liberación, sino por la realidad misma, conscientemente asumida, de entregar la vida por una causa que se ve obligante en conciencia y por una causa que se plantea como causa de los pobres. Todo ello hace que la persecución contra los revolucionarios por causa de la revolución se aproxime a la persecución contra los cristianos, que por medios no estrictamente revolucionarios, coinciden con éstos en apostar por la causa de los pobres y en ofrecer todo su esfuerzo porque prospere esa causa. En este último caso esıán muchos de los esfuerzos de la Iglesia liberadora que combate proféticamente contra el desorden establecido, que presta su apoyo moral a quienes luchan justamente por su liberación, que sjembran una palabra que puede producir frutos revolucionarios. Todo ello significa que la persecución a la Iglesia por causa de la revolución no deja de ser estricta persecución teológica a la Iglesia. Y esto no sólo porque la persecución a los revolucionarios puede tener un sentido leológico y cristiano, sino porque esa coincidencia de propositos no quila que la Iglesia en el modo, en la intención y en la conciencia expresa de su palabra hace de su colaboración revolucionaria parte de su misión eclesial, que exige la promoción de la justicia junto con el anuncio de la fe.

b) Hay también una persecución a la Iglesia, en cuanto la labor de la Iglesia en favor de la causa popular es más direclamente un servicio al pueblo oprimido y no responde con la violencia. La Iglesia es, en este sentido, un reflejo del pueblo, que es masacrado sin que pueda defenderse. Sus hijos no caen en lo lucha armada, caen indefensos, cobardes y vilmente asesinados. Los que cínicamente disculpan a los gobiernos y a los ejércitos asesinos del pueblo y de miembros cualificados de la Iglesia diciendo que no les ocurrirla eso, si no se melieran en "esas cosas", debieran saber bien qué son "esas cosas" y cuál es la manera de meterse en ellas. El pueblo y la Iglesia se meten en los procesos de liberación de modo distinto a como lo hacen los revolucionarios organizados, aun cuando su acción favorezca a éstos como los únicos o los mejores mediadores de la liberación. El apoyo primario de la Iglesia, como decla Monseñor 
Romero, es al pueblo, pero cuando el pueblo está oprimido y masacrado por estructuras e instituciones bien determinadas, a la vez que está defendido por organizaciones bien concretas, la acción de la Iglesia no puede menos de estar objetivamente contra aquellas y en favor de éstas. Las palabras de Juan Pablo I en la audiencia general del 19 de marzo de 1981 indican bien esla primaria solidaridad con los pobres que lleva al asesinato por parte de sus contrarios: "Un año ha pasado desde la trágica muerte del arzobispo Mons. Romero, pastor celoso asesinado el 24 de marzo de 1980 mientras celebraba la santa misa. Así coronó con la sangre su ministerio particularmente solicito con los más pobres y más marginados. Fue un testimonio supremo que ha quedado como símbolo del tormento de un pueblo, pero lambién como causa de esperanza de un porvenir mejor." (Vida Nueva, 27 de junio de 1981, p. 29).

c) Este testimonio eficaz que levania la esperanza del pueblo, que pone en trance de exterminio sediento de sangre a los enemigos del pueblo, ha de seguirse dando aun con graves peligros, pero no de uno manera inconsulica. Es aqui donde la Iglesia universal debería tonar la voz a veces imposible de la lglesia Local; es aquí donde otras Iglesias locales fratemas deberían tomar el lugar de denuncia que a veces le está completa o casi completamente vedado a la lglesia local. Esto no puede suponer nunca el recurso cómodo de escapar al peligro $y$. mucho menos, lo que tanto estamos viendo hoy en Guatemala y El Salvador: que buena parte de la Iglesia, en vez de denunciar la represión hasta llcga a cohonestarla 0 , al menos, a disimular su significado real. Ni puede suponer que la Iglesia local deje de aprovechar su fuerza como un todo y su menor peligro como un todo para llevar su esfuerzo hasta el límite de lo posible. Ni puede suponer tampoco que la Iglesia deje de usar medios menos públicos para continuar su carea eficazmente en favor de la liberación del pueblo y en contra de la represión increlble que sufre ese mismo puebo. Las iglesias locales deben hacer en estos puntos más de lo que hacen y mejor de lo que lo hacen. Pero también las iglesias hermanas y la Iglesia universal tendrían que hacer más y mejor, no tanto en favor de la lglesia misma, sino en favor de pueblos masacrados, cuyo clamor llega hasta el cielo, pero no siempre hasta los ofdos de quienes se dicen sucesores de los apóstoles. No puede negarse que la Iglesia de El Salvador en riempo de Mons. Romero hizo muchísimo y por eso alcanzó el reconocimienro cálido de las iglesias más lejanas y distintas; hoy hace mucho menos, aunque habría modos de hacer, incluso públicos, que no supondrían un peligro desproporcionado. La Iglesia de Guatemala está en peor situación por el tipo de represión, que es propio de las clases dominantes guatemaltecas; pero tampoco puede decirse que ha encontrado un modo cristianamente martirial de proceder. Lo que ocurre en Honduras es de otro estilo, pero tampoco es satisfactorio. Enfrentadas estas iglesias con la persecución, agudizada por la presencia de la revolución, sobre todo las de El Salvador y Guatemala, hay que decir que están lejos de lo que deberían y que están lejos del sacrificio de tantas gentes que no 
se profesan cristianas y que, sin embargo, arriesgan sus vidas por los demás.

d) Mención aparte merece el caso de la Iglesia en Nicaragua. Algunos pretender hacer ver que la revolución ha empezado a perseguir a la Iglesia mostrando así la condición marxista-leninista de la revolución sandinista. Esto no es asi. Pero la posición de parte de la Iglesia, alentada por sectores burgueses de la sociedad, puede traer dificultades, pero esto serfa por su alianza con los sectores burgueses y no por su predicación del reino. No puede decirse que la Iglesia jerárquica nicaragüense $\mathrm{ni}$ la Iglesia institucional fueran perseguidas en el tiempo del somocismo, lo cual es importante para medir el temple cristiano de esa Iglesia; en este sentido, su posición respecto de la Iglesia de El Salvador y aun de la de Guatemala es muy distinta. Pudo colaborar a la caída de Somoza, pero fue en el último momento, mientras que en casi todo el perlodo somocista fue más bien colaboracionista. Parte de ella se muestra hoy más opuesta al sandinismo que lo que fue con el somocismo, lo cual es ya de por sí significativo. Por ello va a empezar a Iener dificultades, pero las dificultades vienen como respuesta a una posjción equivocada de la Iglesia y no a una acción iniciada por el sandinismo; aunque no puede hablarse de persecución, sino de prenuncios de hostigamiento, las dilicultades de este posible hostigamiento no pueden ponerse en la línea de una persecución a la Iglesia, que sería prueba de la autenticidad de la misión cristiana. Lo más grave de esta situación esı́a, sin embargo, en otro punto; está en la pérdida de una ocasión excelente para lograr una revolución original, en la que el cristianismo en vez de ser un freno podría ser una inspiración y una levadura y en la que el cristianismo por su parte podría ser animado y exigido por una revolución puesta al servicio del pueblo. La presencia desde un principio de cristianos y sacerdotes en el proceso sandinista era una garantla de la apertura de la revolución a unas relaciones nuevas con el cristianismo y con la Iglesia. Pero la incompetencia de una jerarquía, que no está a la alıura de las exigencias de una revolución, puede poner graves dificultades al proceso, con pretextos que no tocan el fondo de la cuestión y que hacen el juego a los intereses de las clases burguesas, que son las clases que están promoviendo el conflicto y que están alentando y adulando a los obispos, especialmente a Monseñor Obando, quien les sigue el juego. En estas condiciones, una presunta cruzada anticomunista es un error, especialmente si se considera que esa misma cruzada anticomunista está siendo promovida por la supercapitalista administración de Reagan contra Nicaragua y contra los procesos revolucionarios del área centroamericana. Otra vez, la Iglesia está perdiendo el rumbo y, en vez de medir sus acciones por los intereses de las mayorías populares, mira por sus intereses pasados, por sus rutinas pasadas, que son los intereses y rutinas que se acomodan más a lo que de capitalismo tería el somocismo que a lo que de revolucionario tiene el sandinismo. Se pueden hacer serias críticas al sandinismo, pero siempre que esas críticas no favorezcan a las clases burguesas deseosas de recuperar un poder que han perdido en parte. Esas crílicas deberfan hacerse desde 
posiciones más revolucionarias que las del propio sandinismo, más populares que las del actual gobierno. La Iglesia deberla volcarse en favor de la liberación popular y apoyar entusiásticamente lo que la favorece. Pero yendo a las bases, trabajando con ellas, en vez de mantener un absurdo hostigamiento de poder institucional contra otro poder instilucional. Por otra parte, el sandinismo no debería caer en la trampa porque ciertas formas de hostigamiento podrían alienarle sectores poplares, que no pueden ser fácilmente descalificados como lumpen. Los obispos tienen todavfa una imagen social entre el pueblo, cuya eficacia populista no puede ser desconocida. La esperanza está en que una buena parte de la Iglesia -comunidades de base, sacerdotes y religiosos, laicos comprometidos- no ha entrado en este peligroso juego, sino que, al contrario, se ha puesto claramente en favor de lo que favorece a los más necesitados. Este favorecimiento debe ser crítico y debe evitar identificaciones tolales y ciegas; debe evitar también rompimientos no sólo con la fe y con la Iglesia en general, sino también con la Iglesia institucional concreta, tal como se da en Nicaragua. Esto último, en la medida en que sea posible, porque no es una necesidad teológica absoluta, pero tomado siempre con seriedad.

3.5. La Iglesia en Centroamérica debe manejar cuidadosamnte su doctrina -mil veces rota en la próctica. del no partidismo y de la neutralidad en los procesos políticos partidistas, del estar con todos para poder apoyar a todos, del estar en el centro para que nadie sea excluido:

a) La neutralidad es una posición aceptable y recomendable en determinadas circunstancias, pero puede ser también une actilud de no compromiso y aun de cobardia inaceprable. Es aceptable cuando se es neutral ante organizaciones políticas que se mueven dentro de un mismo ámbito, en el que ofrecen soluciones opinables; es incluso aceptable cuando exige que la Iglesia no se identifique con régimen alguno ni con organización política alguna, por muy buenos que sean o porque sean los mejores en un momento determinado y esto sin duda razonable alguna. Pero no lo es cuando es resultado de una cobardla o una prudencia mal entendida que no sabe distinguir entre el bien y el mal, entre lo que lavorece a las mayorías populares y lo que las daña, entre quienes cometen crímenes contra el pueblo y quienes salen a su defensa... Una neutralidad que no compromete, de la que sólo se sacan ventajas y con la que se evitan riesgos personales e institucionales, incluso riesgos a no equivocarse, no es una neutralidad evangélica, aunque haya sido "sabia" polílica y eclesiástica.

b) No puede haber neutralidad alguna que suponga pacto con la injusticia Esto implica que el no estar con quienes la propician no puede ser un no estar neutral, un no estar precisivo. Debe ser un no estar activo, un no estar condenador, un no estar público y eficaz, combativo. Tal debe ser el caso, por ejemplo, en las situaciones actuales de El Salvador y de Guatemala, donde la Iglesia no tiene que estar con los actuales detentadores del poder, tiene que estar 
en contra de ellos, aunque no estuviera positivamente en favor de sus contrarios, al menos en la misma proporción y grado en que está en contra de los primeros. Esto quiere decir que muchas veces es más claro contra quién se debe estar que a favor de quién. Sin embargo, cuando las opciones versan sobre realidades concretas y determinadas, no caben evasiones teóricas; quiere esto decir, que si urge una coma de posición no cabe eludirla diciendo que ninguna de ellas es perfecta, que habria que buscar una nueva, aunque no sea posible a corto plazo, cuando la solución es urgente a corto plazo. Habría que elegir la menos mala, la más corregible y no prolongar con la indecisión y la neutralidad una situación de desangramiento absolutamente intolerable y en sí misma mucho peor que la solución que puede estimarse como menos mala.

c) Tampoco -o menos aún- puede haber neutralidad ante proyectos políticos, como si todos fueran iguales. No puede medirse el problema de los proyectos con el cliché de los partidismos. Hay proyectos absolutamente intolerables como son en general los proyectos oligárquicos y, o capitalistas de nuestra área centroamericana, sean los que sean los partidos que lo lleven o quieran llevar a cabo. Igualmente puede haber proyectos justos y aun obligatorios sea cual fuere quien los pretenda llevar a cabo. En este caso cabe alistarse con el proyecto y no alistarse con quienes orgánicamente pretender llevarlo a cabo. En general respecto de los proyectos cabe una mayor libertad de compromiso por parte de la Iglesia que respecto de los mecanismos organizativos y políticos, a través de los cuales se realizan. Es la misma distinción que hacíamos antes entre los procesos revolucionarios y las organizaciones que llevan adelante la revolución. Esto es válido tanto para los revolucionarios como para la Iglesia: los revolucionarios oficiales no tiene por qué arrogarse la exclusividad del espfritu revolucionario n la exclusividad del amor al pueblo o de la indignación ante la injusticia; la Iglesia no tiene por qué rechazar o simplemente no comprometerse con la revolución, porque le disgusten las formas en que se encajona la revolución.

d) Si puede ser importante, sin embargo, la neutralidad de la Iglesia ante las diversas organizaciones y, o partidos que están al servicio auténtico del proyecto político necesorio. En estos casos, es o puede ser mayor el peligro del divisionismo que el bien de elegir el "mejor", el peligro de hacer más importante al medio que al fin. Cualquiera sea la libertad que el cristiano tiene para optar por una u otra organización, no es conveniente que la lglesia lo haga, ni en general será conveniente que los hombres que de hecho son vistos como representación más condensada de la Iglesia —obispos, sacerdotes y cuantos tienen algún puesto jerárquico- se adscriban a uno de los medios organizativos. En esto se requiere una gran claridad y una gran sinceridad y en esto tiene sentido el ser factor de unidad, pero no de una unidad abstracta, sino de una unidad que robustezca el proyecto necesario. Desde esta perspectiva hay que ver la participación de sacerdotes en procesos revolucionarios y aun en la gestión política del Estado revolucionario; presencia justificada siempre que favorezca notoriamente 
el proceso necesario y. o pueda aportar seriamente desde su puesto a que el proceso revolucionario se desarrolle en el mejor y mayor servicio a las mayorfas populares y se desarrolle con el mayor espíitu cristiano posible.

4. Frente a los procesos revolucionarios, la actitud de la Iglesiu debiera ser positiva tratando de humanizarlos y, o cristianizarlos, pero no principalmente de forma negativa y destructiva, sino de forma animadora $y$ superadora, aun en aquellos casos en que la revolución misma - y no sólo los revolucionarios- se presenta como no cristiana:

4.1. El espiritu fundamental de acercamiento a la revolución y a los revolucionarios debería ser el de Pablo en su discurso a los atenienses: "Atenienses, en cada detalle observo que son en todo extremadamente religiosos. Porque paseándome por ahí y fijándome en sus monumentos sagrados, encontré incluso un altar con esta inscripción: "Al dios desconocido". Pues eso que veneran sin conocerlo, se lo anuncio yo: el Dios que hizo el mundo y todo lo que contiene. ese que es el Señor de cielo y tierra, no habita en templos construidos por hombres, ni lo sirven manos humanas, como si necesitara de alguien, el que a todos da la vida y el aliento y todo. De un solo hombre saco todas las naciones para que habitaran la faz de la tierra, determinando las etapas de su historia y los límites de sus territorios. Querla que lo buscaran a él, a ver si al menos a tientas io encontraban, por más que no esté lejos de ninguno de nosotros, pues en éi vivimos, nos movemos y existimos. Así lo dicen incluso algunos de sus poetas: "Sí, linaje suyo somos". Por tanto, si somos linaje de Dios, no podemos pensar que la divinidad se parezca a oro, plata o piedra, esculpidos por la destreza y fantasía de un hombre. Pues bien, Dios, pasando por alto aquellos uiempos de ignorancia, manda ahora a todos los hombres en todas partes que se enmienden; porque tiene señalado un día en que juzgará al universo con justicia, por medio del hombre que ha designado, y ha dado loda garantra de esto resucitándolo de la muerte" (Hech 17, 22-31). No vamos a desarrollar aquf este espléndido texto ni en sí mismo ni referido a la revolución. Pero sí insistir en que pone bien en claro cuál es el espíritu con que debe enfrentarse teológica y pastoralmente el problema y así mismo exponer una serie de reflexiones teologicas fundamentales que, incluso en su contenido, son plenamente aplieables al proceso revolucionario, tal como se da entre nosotros. Desde este espiritu y con el desarrollo de estas tesis estariamos en la mejor disposición para acercamos a el no desde la diatriba y desde la condena -como si fuera algo fundamentalmente malo y en donde fuera imposible encontrar la presencia y la acción de Dios-, sino desde la buena nueva que descubre lo bueno, lo alienta y lo transciende, convencidos de que en esos movimientos que han nacido como contradiccion frontal de sistemas injustos y opresores hay un fondo fundamental, no sólo aceptable, sino positivamente enderezado a hacer que el reino de Dios se haga más claro y efectivo entre los hombres. 
4.2. Esto supone indudablemente una verdadera actitud evangélica, una actitud de anuncio que muestra, porque sabe y quiere mostrar, cómo lo mejor del espíritu revolucionario conduce a actitudes cristianas y cómo lo mejor del cristianismo favorece, purifica, robustece y transciende las actitudes revolucionarias. Lo cual exige vivir la plenitud de la fe cristiana y vivirla encarnada en aquellas realidades populares donde da más de sí. Son las mayorías populares el punto de encuentro entre la predicación del evangelio a los pobres y la realización de la revolución de las mayorías oprimidas. Centrado el problema en esa verdad histórica y leológica, puede y debe haber no sólo diferencias, en razón de los distintos intentos 0 , por lo menos, no coincidentes intentos, del cristianismo y de la revolución, sino verdaderas discrepancias crílicas, pero siempre se dará una coincidencia fundamental expresada en la exigencia del "mayor" servicio a lo que son las necesidades, lodas las necesidades, populares. Claro que no debe ser una encarnación dualista como si unos cuidaran del cuerpo y otros del alma o unos de este mundo y otros del más allá. Esa oposición dualista llevará a malos entendidos o a paralelismos precisivos, que serian dos consecuencias malas tanto para la fe cristiana como para la revolución. Peor aún si, tras esa oposición, se esconde una posición de clase o una posición, al menos, que favorece más a la propia institución que al bien del pueblo y, o del reino.

4.3. Supone también un imporiante trabajo teórico tanso a la hora del análisis como a la hora de buscar las mediaciones más adecuadas para que el pueblo reciba el mayor y mejor servicio. Se trata de un problema diffcil y complejo, tanto en la teoría como en la práctica, que no se puede enfrentar con la simplicidad de la ignorancia o de los conocimientos superficiales y, mucho menos, con estereotipos o con análisis mecánicos venidos de fuera. Esto es válido para parte y parte, para los cristianos y los revolucionarios. Todavía no hay un análisis térico salisfactorio de las relaciones entre revolución y cristianismo, ni siquiera de las relaciones entre marxismo y fe cristiana. Pero lo importante no es eso. Porque, aunque sean muy convenientes líneas teoricas generales y universales, lo más importante es determinar aqú y ahora cómo poner en relación constructiva cada una de nuestras revoluciones con la fe cristiana, tal como debe ser vivida en cada una de nuestras repúblicas. Lo importante y lo desafiante está en que entre nosotros ya no es un problema teórico de compaginación de doctrinas, sino un problema real de convergencia de esfuerzos. Sobre todo en casos excepcionales como el de Nicaragua, en donde se ha ofrecido la rara oportunidad de querer hacer una revolución propia y de querer que la fe cristiana y aun la Iglesia participen en el mejoramiento de esa revolución. Pero el caso puede repetirse en Gualemala y El Salvador. Muchísimo depende de lo que haga la Iglesia. Es claro que una Iglesia toda reservas con la revolución no va a estar en las mejores condiciones para participar. Y serfa escandaloso que una Iglesia que ha estado tan pronta a colaborar con sistemas y aun con regímenes tan descaradamente antipopulares y tan violentamente injus- 
los pusiera ahora reparos por prevextos ideologicos, que pueden ofrecer dificultades, pero cuya incidencia en la vida del pueblo es de índole completamente distinta. Todo esto requiere lucidez, trabajo intelectual y no rencillas de sacristía. Sería tristísimo que por falta de lucidez y generosidad se perdiese la oportunidad de demostrar a todo el tercer mundo, y especialmente a los pueblos latinoamericanos, que efectivamente puede haber una verdadera revolución en libertad y en cristianismo. No es hora de perderse en minucias y legalismos, sino de pensar y actuar con profundidad y magnanimidad; no es hora de disputar liderazgos frente al pueblo, ni de buscar la propia clientela para lanzarla contra el adversario. La Iglesia no está para mandar, sino para servir. $Y$ esto no de palabra sino de obra y con los hechos. Su poder está en su capacidad de servir y, sobre todo, su poder estí en el anuncio eficaz de la Palabra de Dios, pero de una Palabra que no salva sino aquello que asume.

5. Es evidente que la misión de la Iglesia no se reduce al horizonte de la revolución y, en ese sentido, no debe preguntarse lo que debe hacer solo desde ese horizonte. Pero éste, en la situación actual de Centroamérica, es de extraordinaria importancia, y esto no tanlo por la revolución misma, sino porque en ella o contra ella se juegan intereses fundamentales del pueblo y de los pobres:

5.1. En este sentido, damos por supuesto que la Iglesia se hace cuestión de anunciar el reino de Dios y de cultivar la dimensión religiosa personal y comunitaria del hombre, de educar en la fe a sus hijos, de impulsarlos a una permanente conversión, de propugnar la expresión litúrgica y, sobre sodo. la celebración de la pascua. Hasta los revolucionarios menos creyentes hablan de las posibilidades del cristianismo para conseguir el hombre nuevo. Debe incluso por su parte atender al crecimiento humano del pueblo, a su asistencia, sobre todo en los momentos de mayor sufrimiento. Pero todo ello no como una acción paralela y, menos, como una acción de competencia, sino como una acción que corrige, complementa y perfecciona. Hay que evitar la politización de la fe como si la fe no fuera más que una superestructura ideológica o polfuca o como si toda la vida humana (la moral, el amor, el dolor, la familia, etc.) fuera política; en todo esto tiene un amplísimo campo la Iglesia, que por su propia naturaleza se acomoda mejor a lo comunitario que a lo sociecario. Pero hay que evitar también la evasión y mucho más la politización a la contra, que consiste en atacar a aquello que favorece las políticas revolucionarias.

5.2. Aun siendo esto asf, sin embargo, el hecho revolucionario -en sus distintas elapas- es en las actuales circunstancias de Centroamérica - con menor urgencia en los casos de Costa Rica y Panama - un hecho histórico fundamental y decisivo, que proféticamente hay que calificarlo como la construcción real de una nueva tierra y un nuevo cielo, una nueva realidad material y una nueva forma de vivirla espiritualmente. Algo que realmente tiene mucho que ver 
con el reino de Dios, aunque no se identifique con ê. Por eso hace mucha falta reflexionar positivamente sobre el sentido teológico de la revolución, porque quizá lo que se aprecia en muchas ocasiones es sólo una reacción eclesiástica y moralizante de corto alcance ante su presencia; reacción espontanejsta y superficial, reacción mecánica y estereotipada. Si algunos revolucionarios, incluso marxistas, ya han visto que el cristianismo puede ser no opio sino fermento, es hora ya también de que la Iglesia - y no sólo algunos cristianos- alcance a ver que la revolución puede ser una fuente profunda de renovación y de sacudimiento, que saque a la Iglesia de muchas de sus inercias y rutinas. No es un hecho más; es un signo de los tiempos.

15 de julio de 1981. 